\title{
APLIKASI E-ORDER MENGGUNAKAN FIREBASE DAN ALGORITME KNUTH MORRIS PRATT BERBASIS ANDROID
}

\author{
Anisya Sonita $^{1}$, Rizki Fitrah Fardianitama ${ }^{2}$ \\ ${ }^{1,2}$ Teknik Informatika, Fakultas Teknik, Universitas Muhammadiyah Bengkulu \\ Jl. Bali Po. Box, 118 Kota Bengkulu 38119 \\ (Telp 0736-22765 Fak. 0736-26161) \\ ${ }^{1}$ anisyasonita@umb.ac.id \\ ${ }^{2}$ rizkifitrah30@gmail.com
}

Abstrak: Semalam Suntuk merupakan salah satu Rumah Makan yang menyediakan masakan khas padang di kota Bengkulu, dengan citarasa yang tidak diragukan lagi. Akan tetapi rumah makan Semalam Suntuk saat ini belum mempunyai sistem pemesanan dengan cara online dan semua pemesanan masih dilakukan secara manual dengan menggunakan telepon atau sms dan media sosial. Tujuan dari penelitian ini adalah merancang dan membangun aplikasi e-order pada rumah makan semalam suntuk berbasis android menggunakan firebase dan algoritme Knuth Morris Pratt. Aplikasi e-order pada rumah makan semalam suntuk berbasis android menggunakan firebase dan algoritme Knuth Morris Pratt berhasil dibuat menggunakan software android studio, aplikasi ini juga menghadirkan pemberitahuan secara otomatis sehingga dapat mempermudah pengguna untuk mendapatkan informasi seputar tentang makanan yang masih tersedia dan dapat menjadi media atau alternatif baru bagi pihak rumah makan dalam memberikan layanan terhadap pelanggan rumah makan semalam suntuk ketika melakukan pemesanan.

Kata Kunci: e-order, algoritme Knuth Morris Pratt, firebase, android, semalam suntuk

\begin{abstract}
Semalam Suntuk is one of the specialties that provide Padang Flavor Restaurant in Bengkulu. But the restaurant Semalam Suntuk not currently have a way online ordering system and all bookings are still done manually by using a phone or sms and social media. The purpose of this study is Designing and Building Applications e-Order On Semalam Suntuk and Android-Based Algorithm Using Firebase and Knuth Morris Pratt, The e-Order On Semalam Suntuk and Android-Based Algorithm Using Firebase Knuth Morris Pratt successfully made using Software Android Studio, this application also presents Notifications automatically so as to facilitate the user to get information about about the food that is still available and can be a media or a new alternative to the restaurant to provide services to residential customers eat an entire night when make a reservation.
\end{abstract}

Keywords: e-Order, Knuth-Morris-Pratt algorithm, firebase, android, semalam suntuk

\section{PENDAHULUAN}

Pemanfaatan teknologi Smartphone berbasis android pada berbagai aspek kini telah dirasakan dampaknya, tanpa terkecuali sampai pada Pengusaha-pengusaha kuliner yang ingin memanfaatkan teknologi demi mendapatkan kepuasan pelanggan dan keuntungan bagi pihak pengusaha. Semalam Suntuk merupakan salah satu Rumah Makan yang menyediakan masakan khas padang di kota Bengkulu, dengan citarasa yang tidak diragukan lagi. Akan tetapi rumah makan Semalam Suntuk saat ini belum mempunyai sistem pemesanan dengan cara online dan semua pemesanan masih dilakukan secara manual dengan menggunakan telepon atau sms dan media sosial.

Manusia pada umumnya menginginkan segala sesuatu dapat dengan mudah dikerjakan, begitu 
Jurnal Pseudocode, Volume V Nomor 2, September 2018, ISSN 2355-5920

www.ejournal.unib.ac.id/index.php/pseudocode

pula dengan pelanggan yang ingin memesan menu dengan mudah dalam artian tidak rumit dan tidak memakan waktu yang lama. Mudah dalam memesan menu yang dimaksud adalah tanpa harus mengantri dan tanpa harus menunggu pelayan yang sibuk dengan pelanggan lainnya. Dari permasalahan yang terjadi, penulis merasa perlu mencari solusi dan merancang suatu aplikasi $e$ Order pada rumah makan Semalam Suntuk yang bersifat portable, dapat diakses dengan mobile device atau smartphone berbasis Android. e-Order merupakan salah satu layanan pemesanan makanan yang sangat popular. Selain mempermudah konsumen dalam mendapatkan makanan, layanan ini juga membantu meningkatkan penjualan bagi pengusaha tersebut, dengan adanya sistem ini pembeli dapat langsung melakukan pemesanan tanpa harus datang ke tempat rumah makan.

\section{Metode Penelitian}

\section{A. Algoritme Sequential Searching}

Algoritme Knuth-Morris-Pratt merupakan salah satu algoritme pencarian string, yang dikembangkan secara terpisah oleh Donald E. Knuth pada tahun 1967 dan James H. Morris bersama Vaughan R. Pratt pada tahun 1966, kemudian dipublikasikan secara bersamaan pada tahun 1977. Algoritme Knuth-Morris-Pratt melakukan perbandingan karakter teks dan karakter pada pola dari kiri ke kanan. Ide dari algoritme ini adalah bagaimana memanfaatkan karakter-karakter pola yang sudah diketahui ada di dalam teks sampai terjadinya ketidakcocokan untuk melakukan pergeseran [3].

Perhitungan pergeseran pada algoritme ini adalah sebagai berikut, bila terjadi ketidakcocokan pada saat pattern sejajar dengan teks $[i . i+$ $n-1]$, kita bisa menganggap ketidakcocokan pertama terjadi di antara teks $[i+j]$ dan Pattern[j], dengan $0<j<n$. Berarti, teks $[i . . i+j-1]=$ pattern $[0 . . j-1]$ dan $a=$ teks $[i+j]$ tidak sama dengan $b=$ pattern $[j]$. Ketika kita menggeser, sangat beralasan bila ada sebuah awalan $v$ dari pattern akan sama dengan sebagian akhiran $u$ dari sebagian teks. Sehingga kita bisa menggeser pattern agar awalan $v$ tersebut sejajar dengan akhiran dari $u[1]$

Secara sistematis, langkah-langkah yang dilakukan algoritme Knuth-Morris-Pratt pada saat mencocokkan string:

1. Algoritme Knuth-Morris-Pratt mulai mencocokkan pattern pada awal teks

2. Dari kiri ke kanan, algoritme ini akan mencocokkan karakter per karakter pattern dengan karakter di teks yang bersesuaian, sampai salah satu kondisi berikut dipenuhi :

a) Karakter di pattern dan di teks yang dibandingkan tidak cocok (mismatch).

b) Semua karakter di pattern cocok. Kemudian algoritme akan memberitahukan penemuan di posisi ini.

3. Algoritme kemudian menggeser pattern berdasarkan tabel, lalu mengulangi langkah 2 sampai pattern berada di ujung teks.

\section{B. Firebase}

Firebase adalah penyedia layanan cloud dengan back-end sebagai servis yang berbasis di San Fransisco, California. Firebase membuat sejumlah produk untuk pengembangan aplikasi Mobile ataupun web. Firebase didirikan oleh Andrew Lee dan James Tamplin pada tahun 2011 
Jurnal Pseudocode, Volume V Nomor 2, September 2018, ISSN 2355-5920

www.ejournal.unib.ac.id/index.php/pseudocode

dan diluncurkan dengan cloud database secara realtime di tahun 2012 [2].

Produk utama dari Firebase yakni suatu database yang menyediakan API untuk memungkinkan pengembang menyimpan dan mensinkronisasi data lewat multiple client. Perusahaan ini diakusisi oleh Google pada Oktober 2014.

Firebase adalah penyedia layanan realtime database dan backend sebagai layanan. Suatu aplikasi yang memungkinkan pengembang membuat API untuk disinkronisasikan untuk client yang berbeda-beda dan disimpan pada cloud-nya
Firebase. Firebase memiliki banyak library yang memungkinkan untuk mengintegrasikan layanan ini dengan Android, Ios, Javacript, Java, Objective-C dan Node.JS . Database Firebase juga bersifat bisa diakses lewat REST API. REST API tersebut menggunakan protokol Server-Sent Event dengan membuat koneksi HTTP untuk menerima push notification dari server. Pengembang menggunakan REST API untuk post data yang selanjutnya Firebase client library yang sudah diterapkan pada aplikasi yang dibangun yang akan mengambil data secara realtime.

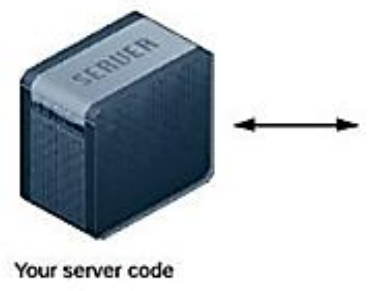

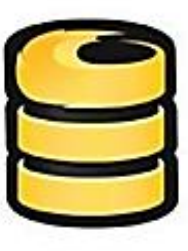

Firebase

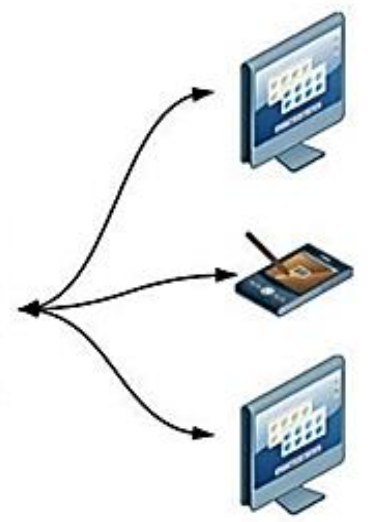

Your client code
Gambar 1. Arsitektur Sistem Firebase

Pengembang juga dapat menggunakan database ini untuk mengamankan data menggunakan server Firebase dengan rules yang ada. Untuk hosting file firebase menyediakan hosting untuk static file dengan fasilitas CND dan SNL.

\section{Model Pengembangan Sistem}

Model sekuensial linier sering disebut siklus kehidupan klasik (classic life cycle) atau model air terjun (waterfall model). Sekuensial linier mengusulkan sebuah pendekatan pada perkembangan perangkat lunak yang sistematik dan sekuensial yang mulai pada tingkat dan kemajuan sistem melalui analisis, desain, pengkodean (coding) dan pengujian (testing) [4]. Model sekuensial linier adalah paradigma rekayasa perangkat lunak paling tua dan paling banyak dipakai.

1. Analisis Kebutuhan

Dilakukan untuk mengetahui spesifikasi kebutuhan untuk sistem dengan mendefinisikan kebutuhan yang dibutuhkan atau persyaratan terkait sistem yang akan dikembangkan. Spesifikasi kebutuhan melibatkan analisis 
perangkat keras (hardware) dan perangkat lunak (software).

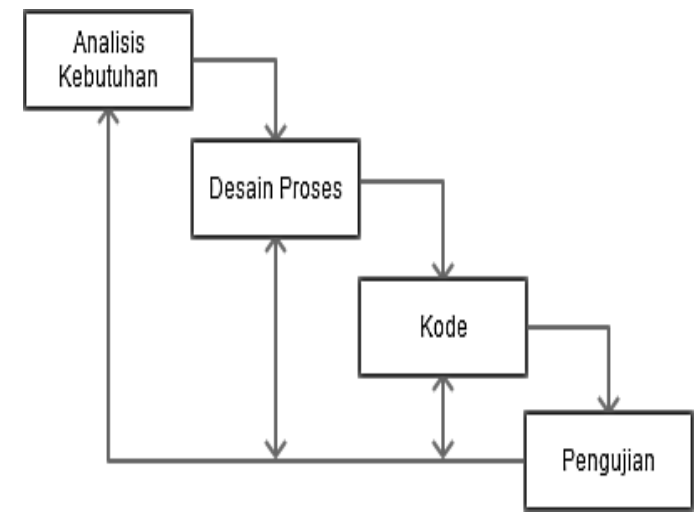

Gambar 2. Sekuensial Linier (Waterfall Model)

1. Analisa Model Aplikasi

Model aplikasi yang akan digunakan berbasis android karena android mudah di kembangkan dan dokumentasinya lengkap selain itu android sudah banyak di gunakan pada perangkat dan gadget modern.

2. Analisa Perangkat Lunak

Perangkat lunak (software) merupakan kumpulan beberapa perintah yang dieksekusi oleh mesin komputer dalam menjalankan pekerjaannya. Adapun perangkat lunak yang digunakan untuk membuat aplikasi e-order pada rumah makan semalam suntuk berbasis android menggunakan firebase ini adalah:
a) Windows 7 Ultimate 32 bit
b) Software Aplikasi Android Studio
c) Bahasa Pemrograman Java
d) Database Firebase

3. Analisa Perangkat Keras

Untuk menjalankan sistem ini diperlukan sebuah personal komputer yang spesifikasinya minimum sebagai berikut:
a) Laptop Lenovo ideapad 100-14
b) Smartphone Android Minimal versi kitkat
c) Processor Intel Inside Core-i3
d) Ram $2048 \mathrm{MB}$
e) Hardisk $500 \mathrm{~GB}$

\section{Desain}

Dalam penelitian ini akan dilakukan proses segmentasi gambar, adapun tugas-tugas yang dibutuhkan untuk membangun satu atau lebih representasi dari aplikasi e-Order pada rumah makan semalam suntuk adalah sebagai berikut :

\section{Flowchart}

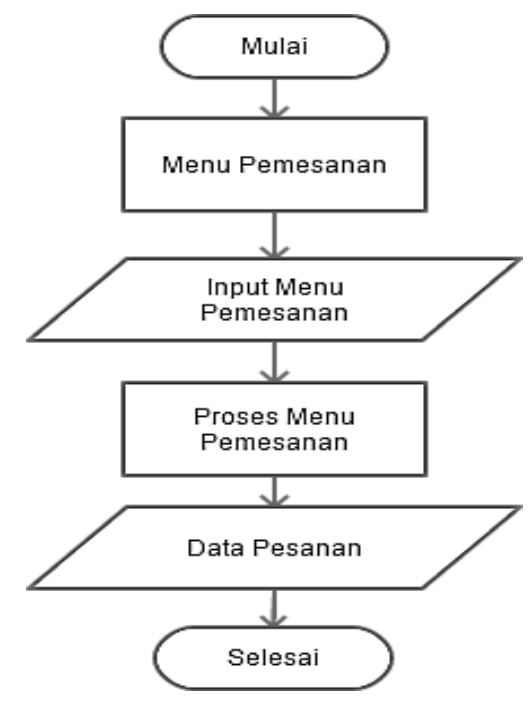

Gambar 3. Flowchart Sistem

\section{Use Case Diagram}

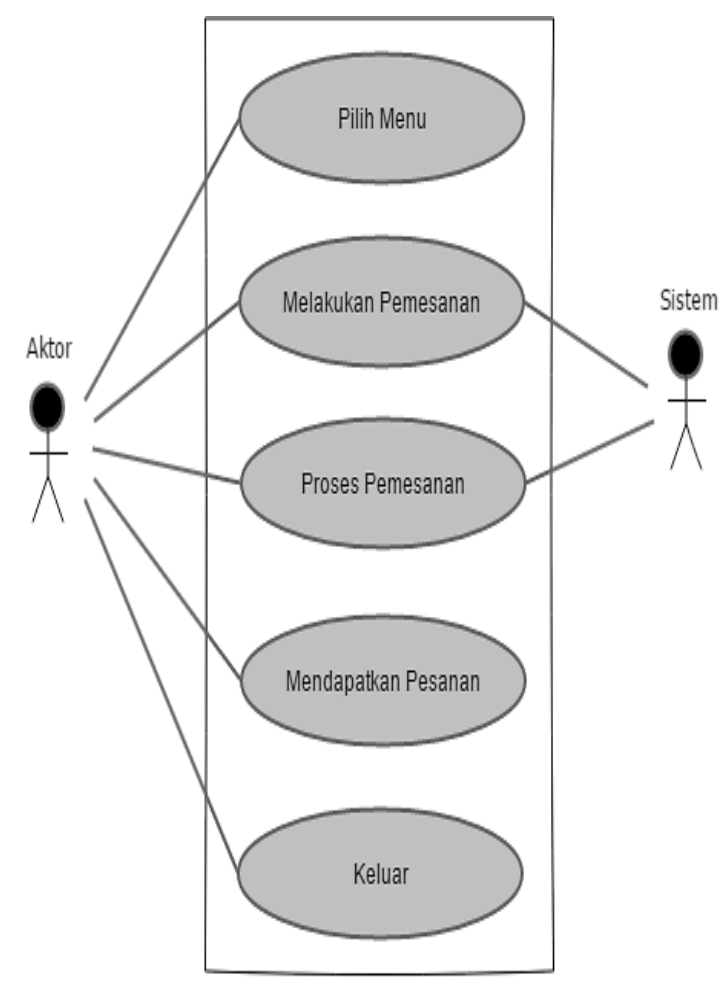

Gambar 4. Use Case Diagram 
3. Activity Diagram

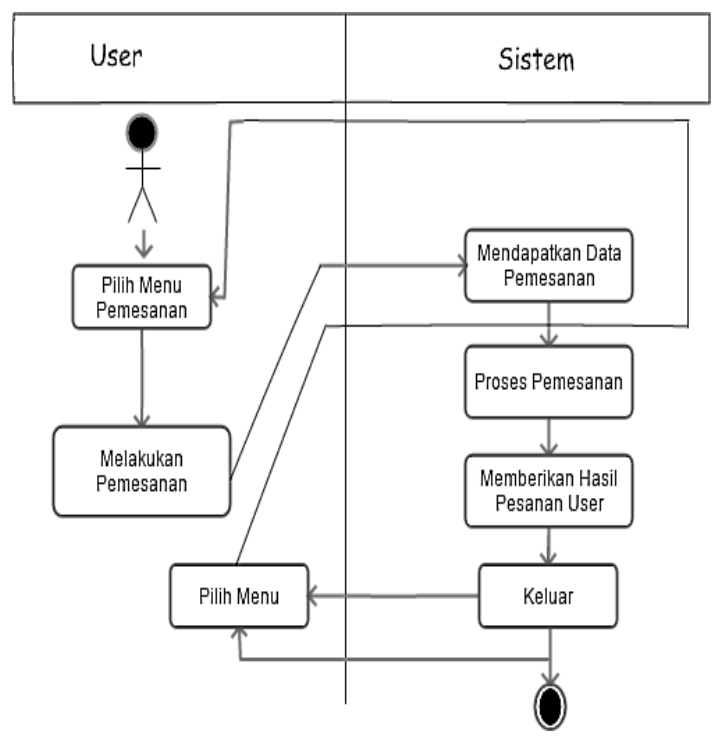

Gambar 5. Activity Diagram

\section{Kode}

Dalam Pembuatan perangkat lunak pengetikan kode program dan struktur logika aplikasi e-order pada rumah makan semalam suntuk penulis menggunakan bahasa pemrograman Java dengan software aplikasi android studio dan database firebase.

4. Pengujian

Adapun proses pengujian sistem dilakukan dengan metode Black Box testing "Metode pengujian Black Box testing adalah tipe testing yang memperlakukan perangkat lunak yang tidak diketahui kinerja internalnya. Sehingga para tester memandang perangkat lunak seperti layaknya sebuah "kotak hitam" yang tidak penting dilihat isinya, tapi cukup dikenal proses testing di bagian luar" [5].

\section{HASIL DAN PEMBAHASAN}

\section{Hasil Penelitian}

Hasil perancangan aplikasi e-order menggunakan firebase dan algoritme Knuth Morris Pratt berbasis android sebagai berikut:
1. Menu Utama

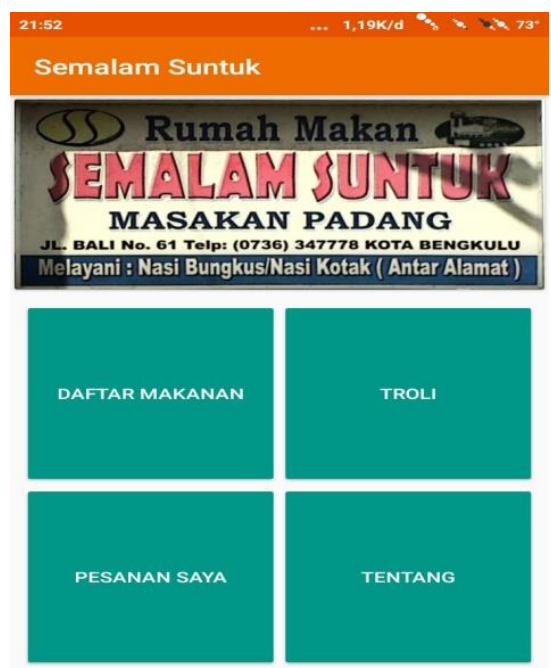

Gambar 6 Menu Utama

Pada Gambar 6 di atas merupakan tampilan dari menu utama user, di mana pada menu utama user ini terdapat menu Daftar Makanan, Troli, Pesanan Saya dan Tentang.

\section{Menu Daftar Makanan}

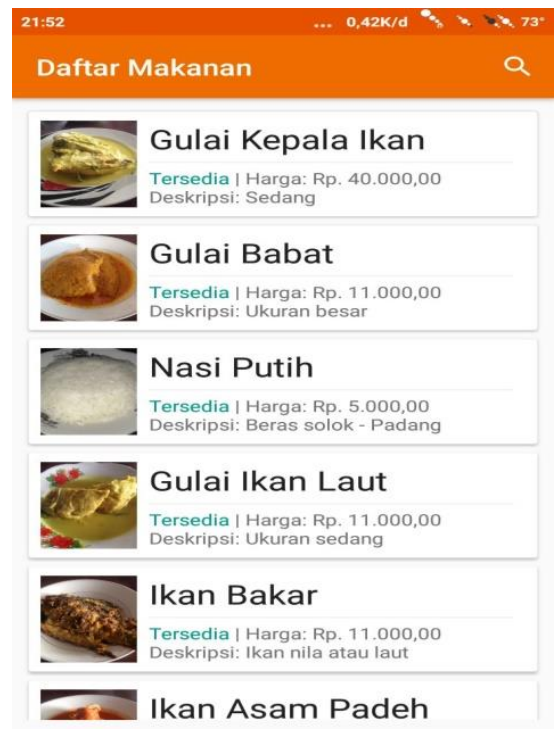

Gambar 7. Menu Daftar Makanan

Menu Daftar makanan ini merupakan tampilan dari daftar-daftar makanan yang ditawarkan oleh penjual. Pengguna dapat mencari menu yang diinginkan sesuai dengan selera sebelum melakukan pesanan. 
3. Menu Pencarian

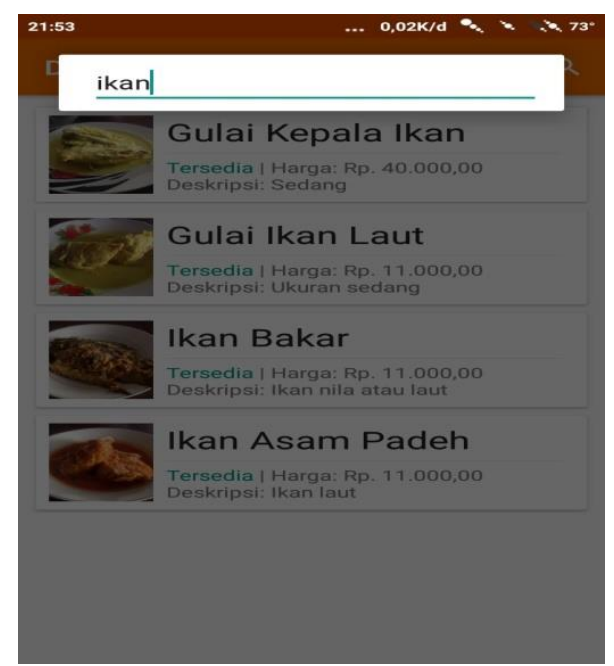

Gambar 8. Menu Pencarian

Gambar 8 di atas merupakan tampilan dari pencarian makanan pada menu user, seperti yang kita lihat pada menu tampilan di atas pada proses pencarian menu makanan yang akan ditampilkan akan menyesuaikan dengan apa yang ditulis atau dicari oleh pengguna pada kolom pencarian, misal yang dicari adalah ikan maka semua menu ikan akan ditampilkan, hal tersebut terjadi karena pada proses pencarian terdapat algoritme Knuth Morris Pratt.

4. Menu Detail Makanan dan Input ke Troli

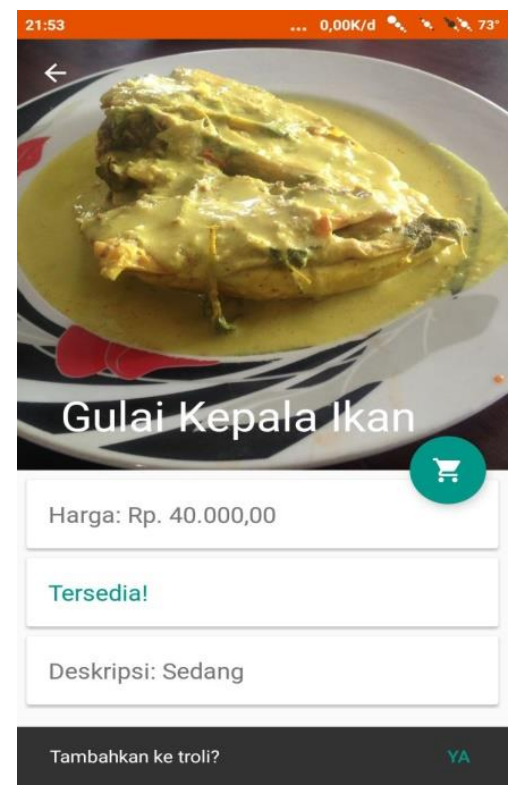

Gambar 9. Detail Makanan dan Input ke Troli
Detail makanan merupakan tampilan ketika pengguna mengetuk salah satu makanan pada menu daftar makanan sebelumnya, selanjutnya jika pengguna ingin melakukan pemesanan pengguna dapat mengetuk tombol dengan icon keranjang troli agar menu tersebut masuk ke dalam troli.

5. Menu Troli dan Proses Pemesanan

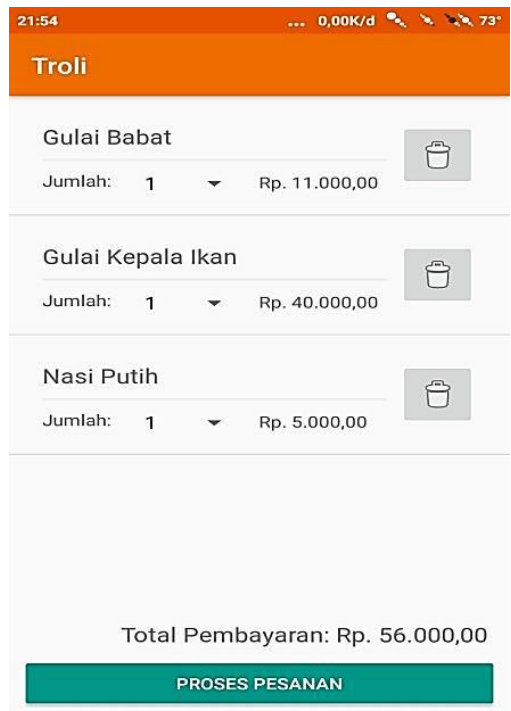

Gambar 10. Menu Troli dan Proses Pemesanan

Menu troli merupakan tampilan dari daftar pesanan pengguna yang telah dipilih dan dimasukkan oleh pengguna pada menu sebelumnya, setelah pengguna merasa yakin dengan pesanan yang dipilih pengguna dapat mengetuk tombol proses agar pesanan dapat diterima dan diproses oleh admin.

6. Menu Pesanan Saya

Pada gambar 11 menu pesanan saya adalah tampilan dari pesanan pengguna setelah pada menu sebelumnya pengguna melakukan proses pesanan. Seperti yang kita lihat pada tampilan gambar di atas terdapat status menunggu konfirmasi berarti pesanan pengguna belum diproses oleh admin, jika admin bersedia memproses pesanan pengguna maka status akan berubah menjadi diterima akan tetapi jika admin tidak bersedia maka statusnya ditolak. 


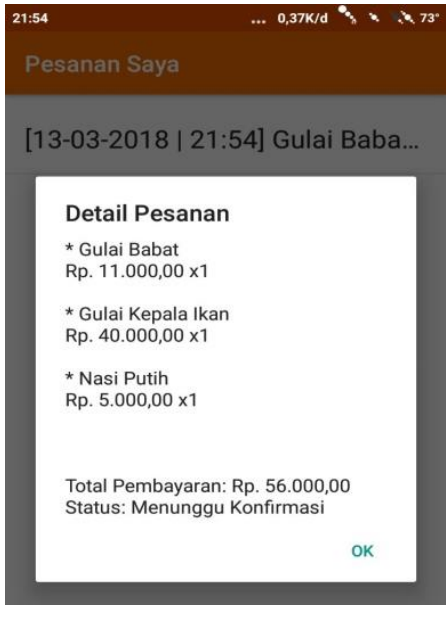

Gambar 11. Menu Pesanan Saya

IV. PEMBAHASAN

\section{Penerapan Algoritme Knuth Morris Pratt}

Berikut adalah pencocokan pattern dari algoritme Knuth-Morris-Pratt pada aplikasi $e$ order rumah makan semalam suntuk:

Teks:

Pattern:

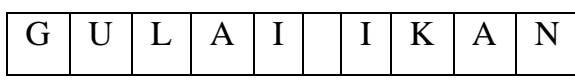

Langkah 1:

\begin{tabular}{|l|l|l|l|l|l|l|l|l|l|}
\hline $\mathrm{G}$ & $\mathrm{U}$ & $\mathrm{L}$ & $\mathrm{A}$ & $\mathrm{I}$ & & $\mathrm{I}$ & $\mathrm{K}$ & $\mathrm{A}$ & $\mathrm{N}$ \\
\hline
\end{tabular}

\begin{tabular}{|l|l|l|l|}
\hline $\mathrm{I}$ & $\mathrm{K}$ & $\mathrm{A}$ & $\mathrm{N}$ \\
\hline
\end{tabular}

Keterangan: Pattern 1 tidak cocok dengan teks 1 maka akan dilakukan pergeseran.

Langkah 2 :

\begin{tabular}{|l|l|l|l|l|l|l|l|l|l|}
\hline $\mathrm{G}$ & $\mathrm{U}$ & $\mathrm{L}$ & $\mathrm{A}$ & $\mathrm{I}$ & & $\mathrm{I}$ & $\mathrm{K}$ & $\mathrm{A}$ & $\mathrm{N}$ \\
\hline
\end{tabular}

\begin{tabular}{|l|l|l|l|}
\hline $\mathrm{I}$ & $\mathrm{K}$ & $\mathrm{A}$ & $\mathrm{N}$ \\
\hline
\end{tabular}

Keterangan: Pattern 1 tidak cocok dengan teks 2 maka akan diberlakukan pergeseran.

Langkah 3 :

\begin{tabular}{|l|l|l|l|l|l|l|l|l|l|}
\hline G & U & L & A & I & & I & K & A & N \\
\hline
\end{tabular}

\begin{tabular}{|l|l|l|l|}
\hline $\mathrm{I}$ & $\mathrm{K}$ & $\mathrm{A}$ & $\mathrm{N}$ \\
\hline
\end{tabular}

Keterangan: Pattern 1 tidak cocok dengan teks 3 maka akan diberlakukan pergeseran.

Langkah 4 :

\begin{tabular}{|c|c|c|c|c|c|c|c|c|c|}
\hline G & U & L & A & I & & I & K & A & N \\
\hline I & K & A & N \\
\hline
\end{tabular}

Keterangan: Pattern 1 tidak cocok dengan teks 4 maka akan diberlakukan pergeseran.

Langkah 5 :

\begin{tabular}{|c|c|c|c|c|c|c|c|c|c|}
\hline G & U & L & A & I & & I & K & A & N \\
\hline \\
$\qquad$\begin{tabular}{|l|l|l|l|}
\hline I & K & A & N \\
\hline
\end{tabular}
\end{tabular}

Keterangan: Pattern 2 tidak cocok dengan teks 6 maka akan diberlakukan pergeseran.

Langkah 6 :

\begin{tabular}{|l|l|l|l|l|l|l|l|l|l|}
\hline G & U & L & A & I & & I & K & A & N \\
\hline
\end{tabular}

\begin{tabular}{|c|c|c|c|}
\hline I & $\mathrm{K}$ & $\mathrm{A}$ & $\mathrm{N}$ \\
\hline
\end{tabular}

Keterangan: Pattern 1 sampai 4 cocok dengan teks 7 sampai 10 maka tidak diperlukan lagi pergeseran.

\section{KESIMPULAN}

Berdasarkan hasil dari perancangan dan pengujian yang telah dilakukan pada aplikasi eorder pada rumah makan semalam suntuk berbasis android menggunakan firebase dan algoritme Knuth Morris Pratt dapat diambil kesimpulan sebagai berikut:

1. Aplikasi $e$-Order pada rumah makan semalam suntuk berbasis android menggunakan firebase dan algoritme Knuth Morris Pratt berhasil dibuat menggunakan software android studio.

2. Aplikasi yang dibuat menghadirkan Pemberitahuan secara otomatis sehingga dapat mempermudah pengguna atau user untuk mendapatkan informasi seputar tentang makanan yang masih tersedia.

3. Aplikasi $e$-Order pada rumah makan semalam suntuk ini dapat menjadi media atau alternatif baru bagi pihak rumah makan dalam memberikan layanan terhadap pelanggan rumah makan semalam suntuk ketika melakukan pemesanan. 
Jurnal Pseudocode, Volume V Nomor 2, September 2018, ISSN 2355-5920

www.ejournal.unib.ac.id/index.php/pseudocode

\section{REFERENSI}

[1] Astuti, Wistiani. 2017. Analisis String Matching Pada Judul Skripsi Dengan Algoritme Knuth-Morris Pratt (KMP). ILKOM Jurnal Ilmiah Volume 9 Nomor 2.

[2] Evangelist, Pram. 2015. Apa itu Firebase?. Retrieved 2 Maret 2015, from https://idevangelist.com/2015/10/apaitufirebase/

[3] Mulyawati, Subagio dan Martha. 2017. Implementasi Metode String Matching Untuk Aplikasi Pengarsipan
Dokumen (studi kasus : SMPN 3 sumber kab. Cirebon). JURNAL DIGIT, Vol. 7 No.1.

[4] Pressman, Roger, S. 2001. Software Engineering: A Practitioner's Approach, Fifth Ed. New York, McGrawHill Book Company.

[5] Soetam, Rizky. 2011. Konsep Dasar Rekayasa Perangkat Lunak (Sofware Reenginering). Prestasi Pustaka Publisher, Jakarta. 